\title{
Evaluación química y emisión de gas In-vitro en ensilados mixtos de King Grass y Clitoria-ternatea
}

\author{
Chemical evaluation and In-vitro gas emission in mixed King Grass and \\ Clitoria-ternatea silages
}

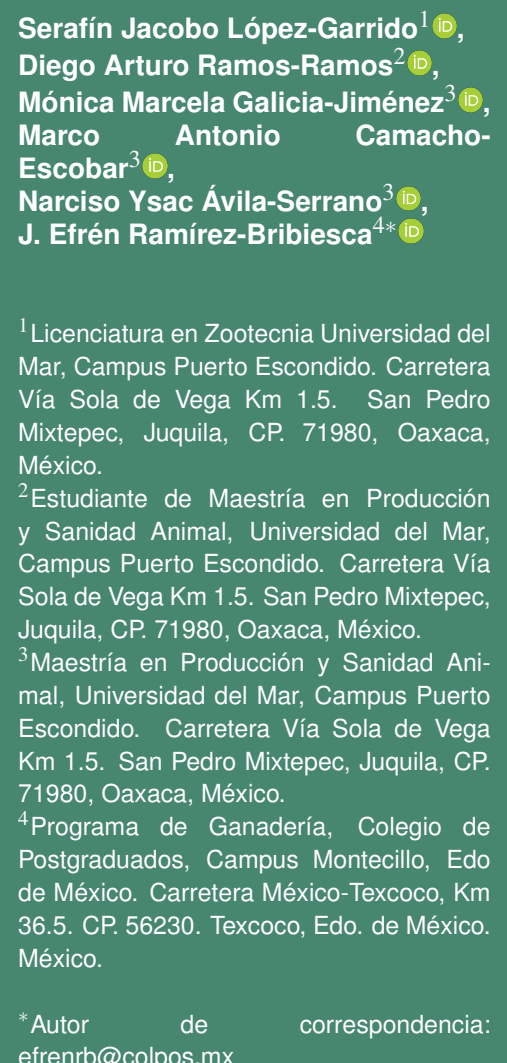

efrenrb@colpos.mx

Artículo científico

Recibido: 06 de marzo 2021

Aceptado: 20 de octubre 2021

Como citar: López-Garrido SJ, RamosRamos DA, Galicia-Jiménez MM, Camacho-Escobar MA, Ávila-Serrano NY, Ramírez-Bribiesca JE (2021) Evaluación química y emisión de gas In-vitro en ensilados mixtos de King Grass y Clitoriaternatea. Ecosistemas y Recursos Agropecuarios Núm. Esp. II: e2973. DOI: 10.19136/era.a8nll.2973
RESUMEN. El estudio evaluó la composición química, degradabilidad de la materia seca, producción de metano $\left(\mathrm{CH}_{4}\right)$ y dióxido de carbono $\left(\mathrm{CO}_{2}\right)$ en ensilados mixtos. Se realizaron micro silos de King grass CT-115 (Pennisetum purpureum Schumach) con la inclusión de 20, 30 y $40 \%$ de Clitoria ternatea adicionando de $5.0 \%$ de melaza y $0.5 \%$ de ácido fosfórico. Después de 40 días de fermentación, se determinó materia seca (MS), proteína cruda (PC), fibra detergente neutro (FDN), fibra detergente ácido (FDA), pH, nitrógeno amoniacal (NA) y ácidos grasos volátiles (AGV). La fermentación in vitro realizada midió la degradabilidad de la materia seca, emisiones de $\mathrm{CH}_{4}$ y $\mathrm{CO}_{2}$ a las 24, 48 y $72 \mathrm{~h}$. La inclusión de Clitoria ternatea en los ensilados aumentó el contenido de MS y $P C(P<0.05)$ y disminuyeron $(P<0.05)$ los porcentajes de FDN y FDA. El pH fue menor a $4.5(P<0.05)$ con la adición de ácido fosfórico. Las concentraciones de AGV y de NA indicaron buena calidad de los ensilados. La inclusión de $40 \%$ de Clitoria ternatea en los ensilados produjo una disminución de $27 \%$ de $\mathrm{CH}_{4}(\mathrm{P}<0.05)$ durante la fermentación in vitro. Como conclusión, la inclusión de $40 \%$ de Clitoria ternatea en ensilados de King grass CT-115 mejora la composición química y disminuye las emisiones de $\mathrm{CH}_{4}$ durante la fermentación ruminal in vitro.

Palabras clave: Composición química; fermentación microsilos; forrajes; gases efecto invernadero.

ABSTRACT. The study evaluated the chemical composition, dry matter degradability, methane $\left(\mathrm{CH}_{4}\right)$ and carbon dioxide $\left(\mathrm{CO}_{2}\right)$ production in mixed silage. Micro silos of King grass CT-115 (Pennisetum purpureum Schumach) were made with the inclusion of 20,30 and $40 \%$ of Clitoria ternatea adding $5.0 \%$ molasses and $0.5 \%$ phosphoric acid. After 40 days of fermentation, dry matter (DM), crude protein (PC), neutral detergent fiber (NDF), acid detergent fiber (ADF), $\mathrm{pH}$, ammonia nitrogen (NA) and volatile fatty acids (VFA) were determined. The in vitro fermentation carried out measured dry matter degradability, $\mathrm{CH}_{4}$ and $\mathrm{CO}_{2}$ emissions at 24, 48 and $72 \mathrm{~h}$. The inclusion of Clitoria ternatea in the silages increased the content of DM and $P C(P<0.05)$ and decreased $(P<0.05)$ the percentages of NDF and FDA. The pH was less than $4.5(P<0.05)$ with the addition of phosphoric acid. The VFA and NA concentrations indicated good quality of the silage. The inclusion of $40 \%$ of Clitoria ternatea in the silage produced a decrease of $27 \%$ of $\mathrm{CH}_{4}(\mathrm{P}<0.05)$ during in vitro fermentation. In conclusion, the inclusion of $40 \%$ of Clitoria ternatea in King grass CT-115 silages improves the chemical composition and reduces $\mathrm{CH}_{4}$ emissions during in vitro ruminal fermentation.

Key words: Chemical composition; micro-silos fermentation; forages; greenhouse gases. 


\section{INTRODUCCIÓN}

Los rumiantes tienen la capacidad de aprovechar los forrajes fibrosos como fuentes de energía a través de la producción de ácidos grasos volátiles (AGV) (Carmona et al. 2005). Sin embargo, durante la fermentación ruminal se originan productos finales como el dióxido de carbono $\left(\mathrm{CO}_{2}\right)$ y metano $\left(\mathrm{CH}_{4}\right)$. Estos gases contribuyen al calentamiento global y forman parte de los gases de efecto invernadero (GEI), representando una pérdida de la energía total consumida por parte del rumiante que va de 7 al 15\% (Barros et al. 2014).

En los últimos años se han implementado estrategias para reducir las emisiones de $\mathrm{CH}_{4}$ por el potencial negativo de GEI, que es de 21 a 30 veces más que el $\mathrm{CO}_{2}$ (McCaughey et al. 1997). El consumo de los pastos tropicales por los rumiantes, induce a mayores emisiones de $\mathrm{CH}_{4}$, debido a los bajos contenidos de proteína cruda (PC) y el alto contenido de paredes celulares, disminuyendo la degradabilidad de materia seca (MS) en el rumen (Sánchez 2005, Juárez et al. 2009). Los pastos tropicales tienen alta cantidad de celulosa y hemicelulosa, estos polímeros son fermentados por bacterias celulolíticas que transforman la glucosa en acetato y butirato, produciendo en la ruta metabólica iones hidrógeno y $\mathrm{CO}_{2}$; posteriormente estos sustratos los utilizan las Archaeas metanogénicas y forman $\mathrm{CH}_{4}$ (Hill et al. 2016). Algunos autores citan que las emisiones de $\mathrm{CH}_{4}$ disminuyen con la inclusión de especies arbóreas y leguminosas tropicales en la dieta de los rumiantes (Cárdenas et al. 2003). Entre las leguminosas destaca la Clitoria ternatea, con 16 a $21 \%$ de PC (Bustamante 2004) y un contenido menor a $40 \%$ en paredes celulares (Bugarín et al. 2009). Una de las estrategias que permiten la adecuada conservación y la calidad de los nutrientes de las leguminosas es mediante el ensilaje. En las condiciones del trópico, la elaboración de ensilados es una alternativa que puede conservar el forraje excedente producido en la época de lluvia y utilizado en la temporada de sequía (Cárdenas et al. 2003). Generalmente los ensilados se elaboran con gramíneas que tienen baja cantidad de proteína, alto valor de fibra y baja cantidad de carbohidratos solubles (McDonald et al. 2011). El contenido de azúcares en los ensilados es necesario para tener una adecuada fermentación láctica, sin embargo, el bajo contenido de PC limita el valor nutritivo del ensilado (Cárdenas et al. 2003). Adicionalmente, la Clitoria ternatea ha sido incorporada a los silos de gramíneas entre 20 y $50 \%$ con el propósito de aumentar los contenidos de PC y minerales (Villanueva et al. 2004), pero este forraje tiene bajo contenido de azúcares solubles, las consecuencias durante el proceso del ensilaje es la baja fermentación y el aumento de amoniaco; antagonizando la disminución del pH hasta 4.0 (Cárdenas et al. 2003). Por lo tanto, es necesario adicionar a los ensilados mixtos de gramíneas y leguminosas una fuente de carbohidratos solubles, como la melaza, para realizar una fermentación láctica (Heinritz et al. 2012). Durante la fermentación del ensilaje proliferan bacterias acido lácticas formadoras de ácidos orgánicos como láctico, acético, propiónico y a menor concentración el butírico; todos estos acidifican el ensilado causando un descenso del $\mathrm{pH}$ hasta 4.0 (Hafner et al. 2013), sin alterarse la composición química del ensilado hasta su apertura (Santos da Silva et al. 2014).

La fermentación acético-propiónico en los ensilados se ha obtenido con el uso de aditivos como el ácido fosfórico (disminuye el pH a 5.0), induciendo la fermentación anaerobia para la producción de ácidos orgánicos (Duniére et al. 2013). La inclusión de leguminosas tropicales en los ensilados tiene el propósito de corregir las deficiencias de proteínas que presentan las gramíneas. Sin embargo, algunas investigaciones han reportado que suplementos con alfalfa y trébol en las dietas para el ganado aumentaron las emisiones de $\mathrm{CH}_{4}$ ruminal (Carulla et al. 2005). Por su parte, Vargas et al. (2012) después de realizar una amplia revisión sobre la emisión de $\mathrm{CH}_{4}$ en dietas mixtas de gramíneas y leguminosas, concluyeron diferentes respuestas y resultados contradictorios. En las investigaciones sobre emisiones de GEI en silos mixtos de gramíneas y leguminosas tropicales aún existe poca información. El objetivo de este estudio fue determinar la composición química, medir la degradabilidad de la MS y cuantificar las emi- 
siones de $\mathrm{CH}_{4}$ y $\mathrm{CO}_{2}$ in vitro con ensilados de King grass CT-115 (Pennisetum purpureum Schumach) e incorporando los contenidos de 20,30 y $40 \%$ de Clitoria ternatea con la adición de $5.0 \%$ de melaza y 0.5\% de ácido fosfórico.

\section{MATERIALES Y MÉTODOS}

\section{Lugar de estudio}

El cultivo se realizó durante la época de lluvia en el Campo Experimental de la Universidad del Mar, ubicada en Puerto Escondido, San Pedro Mixtepec Juquila, Oaxaca, México. Se sembraron superficies de pasto King grass (CT-115) en el área de una hectárea con uso del suelo al mínimo laboreo a $0.90 \mathrm{~m}$ entre cada surco de sembrado. En el caso de la Clitoria ternatea, la siembra se realizó manualmente a $80 \mathrm{~cm}$ de distancia del surco, introduciendo la semilla a una profundidad de $2 \mathrm{~cm}$ considerando una densidad de 38 semillas por cada $\mathrm{m}^{2}$. Posteriormente las muestras de forrajes se cosecharon al inicio de la floración, realizando cortes aleatorios a los 45 y 60 días después de la siembra, respectivamente. Estas fueron representativas de cada superficie y no estuvieron contaminadas de materia vegetativo muerto $\mathrm{u}$ otras variedades de plantas y contaminantes de suelo. Los análisis se realizaron en el Laboratorio de Bioquímica y Nutrición de la Licenciatura en Zootecnia, Universidad del Mar, y en el Laboratorio de Nutrición Animal del programa de Ganadería del Colegio de Postgraduados, Campus Montecillo, Municipio de Texcoco, Estado de México.

\section{Asignación de los tratamientos}

Las muestras de los forrajes se picaron a un tamaño de particula de menos de un centímetro. Posteriormente los tratamientos se distribuyeron con las siguientes mezclas: $\mathrm{C} 20 \mathrm{f}=75 \%$ de pasto King grass $+20 \%$ de C. ternatea $+4.5 \%$ de melaza $+0.5 \%$ de ácido fosfórico; $\mathrm{C} 20=75 \%$ de pasto King grass + $20 \%$ de $C$. ternatea $+5.0 \%$ de melaza; C $30 f=65 \%$ de pasto King grass $+30 \%$ de C. ternatea $+4.5 \%$ de melaza $+0.5 \%$ de ácido fosfórico; C30 $=65 \%$ de pasto King grass $+30 \%$ de C. ternatea $+5.0 \%$ de melaza; $\mathrm{C} 40 \mathrm{f}=55 \%$ de pasto King grass $+40 \%$ de
C. ternatea $+4.5 \%$ de melaza +0.5 de ácido fosfórico; $\mathrm{C} 40=55 \%$ de pasto King grass $+40 \%$ de $C$. ternatea $+5.0 \%$ de melaza. Se elaboraron microsilos fabricados con policloruro de vinilo (PVC) de cuatro pulgadas de diámetro, se llenaron por quintuplicado con $1.4 \mathrm{~kg}$ de cada tratamiento; cantidad necesaria para facilitar la compactación, el sellado y almacenamiento a temperatura ambiente en condiciones de laboratorio $\left(21^{\circ} \mathrm{C}\right)$ por 40 días para darse el proceso de fermentación del ensilaje.

\section{Análisis químico de los ensilados}

Después de la fermentación, los microsilos se destaparon y se tomaron $300 \mathrm{~g}$ muestras de cada unidad experimental, secándose a $45^{\circ} \mathrm{C}$ por $48 \mathrm{~h}$ en una estufa de aire forzado. Las muestras se le determinó las cantidades de MS, PC (AOAC 1995) fibra detergente neutro (FDN) y fibra detergente ácido (FDA) (Georing y Van Soest 1970). pH: Se pesaron $50 \mathrm{~g}$ de cada tratamiento en matraces Erlenmeyer de $250 \mathrm{~mL}$, aforándose con $100 \mathrm{~mL}$ de agua destilada; posteriormente las mezclas se molieron en una licuadora, se reposaron por 20 minutos y se cuantificó el $\mathrm{pH}$ con un potenciómetro portátil Orion 290. Ácidos grasos volátiles: Las muestras se analizaron con un equipo de cromatografía de Gases Perkin Elmer ${ }^{\circledR}$ Clarus 500, U.S.A. con un detector de ionización con flama, automuestreador y una columna capilar Elite FFAP. Las condiciones de trabajo fueron: temperatura de horno $130^{\circ} \mathrm{C}$, y del inyector y la columna capilar $(15 \times 0.32 \mathrm{~m}) 250^{\circ} \mathrm{C}$. Los tiempos de retención fueron $1.26 \mathrm{~min}$ para acetato, $1.6 \mathrm{~min}$ propionato y $2.09 \mathrm{~min}$ butirato. Nitrógeno amoniacal: Se determinó con la técnica descrita po McCullough (1967). Se usaron las mismas muestras preparadas para medir los AGV. Se tomaron $2 \mathrm{~mL}$ de la solución y se centrifugaron a $3500 \mathrm{rpm}$ por 25 minutos. El sobrenadante de la muestra se tomó y vertió en viales de $2.5 \mathrm{~mL}$, almacenándose en refrigeración a $4^{\circ} \mathrm{C}$ hasta su análisis. La absorbancia se registró en un espectrofotómetro de luz ultravioleta visible Varian CARY 1-E a $630 \mathrm{~nm}$.

\section{Fermentación in vitro de los ensilados con líquido de rumen}

Obtención del líquido de rumen: Se uti- 
lizaron 3 ovinos machos de 1 año de edad canulados en rumen. Los animales estuvieron alimentados con una dieta de forraje y concentrado a 70 (King grass y Clitoria ternatea): 30\% (ensilado). Los animales se mantuvieron bajo el cuidado de la norma sobre el Uso de los Animales para Experimentación que está vigente en el Colegio de Postgraduados. La muestra de líquido de rumen se colectó de todos los animales, filtrándose en 3 capas de manta de cielo y mezclándose en un termo a temperatura interna de $39^{\circ} \mathrm{C}$, durante la mañana. El líquido de rumen conservado se transportó al laboratorio en un tiempo máximo de 5 minutos para utilizarse en la preparación del cultivo in vitro de las muestras experimentales.

Fermentación de gas In vitro: Las dietas experimentales se molieron en un molino (Wiley ${ }^{\circledR}$ malla de $2 \mathrm{~mm}$ ) y se pesaron $0.5 \mathrm{~g}$ de MS de muestra con 6 repeticiones por tratamiento en viales de $120 \mathrm{~mL}$. Posteriormente se les agregó $45 \mathrm{~mL}$ de medio de cultivo con el líquido de rumen a cada vial, bajo condiciones anaeróbicas con el flujo de $\mathrm{CO}_{2}$. La producción de gas $\left(\mathrm{CH}_{4}\right.$ y $\left.\mathrm{CO}_{2}\right)$ se cuantificó mediante la técnica descrita por Krabill et al. (1969) y modificada por Cobos et al. (2018). Los viales se incubaron en un baño María a $39^{\circ} \mathrm{C}$, colocándose trampas de captura del gas a través de una manguera Tygon ${ }^{\circledR}$ con un diámetro interior de $3 / 32$ " y agujas marca Terumo ${ }^{\circledR}$ de calibre 20 GX1" en cada extremo. La aguja del primer extremo de la manguera se colocó al vial y la otra a la trampa de captura del gas que contenía solución salina saturada. La producción del gas total se cuantificó midiendo el desplazamiento del líquido de las trampas en la probeta a las 24, 48 y $72 \mathrm{~h}$ de fermentación. Posteriormente se tomó una muestra de $500 \mu \mathrm{L}$ del gas atrapado para medir las proporciones de $\mathrm{CH}_{4}$ y $\mathrm{CO}_{2}$ por cromatografía de gases (mismo equipo descrito anteriormente). Las condiciones de detección fueron las siguientes: temperaturas de horno $80^{\circ} \mathrm{C}$, columna empacada $170^{\circ} \mathrm{C}$ y detector de conductividad térmica $130^{\circ} \mathrm{C}$; los tiempos de retención fueron 0.71 y 1.005 min para $\mathrm{CH}_{4}$ y $\mathrm{CO}_{2}$, respectivamente. EI gas acarreador fue helio con un flujo de $23 \mathrm{~mL} \mathrm{~m}^{-1}$. La concentración molar de $\mathrm{CH}_{4}$ y $\mathrm{CO}_{2}$ se calcularon según la ecuación de los gases ideales (Posada y
Noguera 2005).

La cuantificación de la degradabilidad In vitro de la materia seca (DIVMS) se obtuvo a las $72 \mathrm{~h}$ filtrando las muestras con papel Whatman hasta las $72 \mathrm{~h}$ de incubación. Se incluyeron las muestras testigo (solo líquido de rumen sin muestra) y los tratamientos, aplicando la fórmula siguiente: DIVMS $=1-\mathrm{R}$ $\mathrm{BS}$, donde $\mathrm{R}(\mathrm{g}$ ) es el peso del residuo del sustrato, $\mathrm{B}(\mathrm{g})$ es el peso del residuo del blanco y $\mathrm{S}$ es la MS peso del sustrato inicial.

\section{Análisis estadístico}

El análisis estadístico se condujo mediante un diseño experimental completamente aleatorio con seis tratamientos y cinco repeticiones. La información se analizó con el programa estadístico SAS (2010) a través de PROC GLM, considerando el efecto de los tratamientos para las variables fisicoquímicas de los ensilados y los efectos de tratamientos y tiempos (analizado solo en los tratamientos) para las variables de fermentación In vitro. La comparación de medias se realizó con el estadístico de prueba Tukey (Steel y Torrie 1988) a una significancia menor de 0.5.

\section{RESULTADOS}

\section{Análisis químico de los ensilados}

La Tabla 1 muestra los resultados de la composición química de los ensilados a los $40 \mathrm{~d}$ de fermentación. El porcentaje de MS fue mayor $(P<0.05)$ en los ensilados que contenían 30 y $40 \%$ de Clitoria ternatea, los resultados indican que a medida que aumenta la inclusión de la leguminosa, se incrementa el contenido de MS; la adición de ácido fosfórico no tuvo efecto sobre el contenido de MS en los ensilados.

El contenido de $P C$ fue mayor $(P<0.05)$ en los ensilados con $40 \%$ de Clitoria ternatea, (10.21 vs. $8.6 \%$ ), comparada con los demás tratamientos. En el caso del ensilado con $20 \%$ de Clitoria ternatea, el grupo con ácido fosfórico (C20f) aumentó un 13\% la proteína. Adicionalmente, los ensilados con $40 \%$ de Clitoria ternatea tuvieron menores $(P<0.05)$ cantidades de FDN y FDA.

Por otro lado, se obtuvo un $\mathrm{pH}$ menor $(\mathrm{P}<$ 0.05 ) en el ensilado C20f que contenía $20 \%$ de Clito- 
Tabla 1. Composición química de ensilados mixtos de King grass CT-115 con Clitoria ternatea.

\begin{tabular}{lrrrrrrr}
\hline Componentes, \% & C20f & C20 & C30f & C30 & C40f & C40 & EEM $^{1}$ \\
\hline Materia seca & $28.52^{c}$ & $28.90^{c}$ & $31.15^{b}$ & $31.59^{b}$ & $32.73^{a b}$ & $33.34^{a}$ & 0.33 \\
Proteína cruda & $9.23^{b}$ & $8.19^{c}$ & $8.50^{b c}$ & $8.51^{b c}$ & $10.31^{a}$ & $10.12^{a}$ & 0.21 \\
Fibra detergente neutro & $66.15^{a}$ & $65.80^{a}$ & $65.48^{a}$ & $64.38^{a}$ & $59.56^{b}$ & $59.26^{b}$ & 0.89 \\
Fibra detergente ácido & $49.16^{a}$ & $48.35^{a}$ & $47.04^{a}$ & $48.39^{a}$ & $45.61^{a b}$ & $42.18^{b}$ & 0.73 \\
\hline abc Medias con literales diferentes en la misma hilera indican diferencia $(\mathrm{P}<0.05) .{ }^{1}$ EEM: Error \\
estándar de la media. C20f: 75\% de King Grass + 20\% de Clitoria ternatea + 4.5\% de melaza + 0.5 \\
\% de ácido fosfórico. C20: 75\% de King Grass + 20\% de Clitoria ternatea + 5.0\% de melaza. C30f: \\
65\% de King Grass + 30\% de Clitoria ternatea + 4.5\% de melaza + 0.5\% de ácido fosfórico. C30: \\
65\% de King Grass + 30\% de Clitoria ternatea + 5.0\% de melaza. C40f: 55\% de King Grass + 40\% \\
de Clitoria ternatea + 4.95\% de melaza + 0.05\% de ácido fosfórico. C40: $55 \%$ de King Grass + 40\% \\
de Clitoria ternatea + 5.0\% de melaza.
\end{tabular}

ria ternatea y ácido fosfórico (Tabla 2). Por otro lado, se obtuvo un $\mathrm{pH}$ menor $(\mathrm{P}<0.05)$ en el ensilado C20f que contenía $20 \%$ de Clitoria ternatea y ácido fosfórico (Tabla 2). El ensilado con $30 \%$ de Clitoria ternatea (C30f) registró la mayor producción de AGV $(P<0.05)$. El ácido propiónico fue el de mayor proporción $(P<0.05)$ a diferencia de todos los demás tratamientos; en el caso de C40 o C40f no tendió a mejorar la proporción de los AGV, pero fue mayor ( $P$ $<0.05$ ) el contenido de N-Total vs. C20f y C20.

\section{Fermentación in vitro de los ensilados}

La DIVMS de los ensilados no presentó cambios $(P>0.05)$ con la inclusión de la leguminosa. Solamente el ensilado C30f con 30\% de Clitoria ternatea y ácido fosfórico incrementó el porcentaje $(P<0.05)$ de DIVMS (Tabla 3). Todos los ensilados tuvieron una DIVMS entre 51.13 a $54.79 \%$.

La Tabla 3 muestra las emisiones de $\mathrm{CH}_{4}$ y $\mathrm{CO}_{2}$ de los tratamientos. Los ensilados con $20 \mathrm{y}$ $30 \%$ de Clitoria ternatea presentaron mayores $(\mathrm{P}<$ 0.05 ) emisiones de $\mathrm{CH}_{4}$ a las $24 \mathrm{~h}$. En los ensilados con $40 \%$ de Clitoria ternatea la emisión de $\mathrm{CH}_{4}$ disminuyó $27.6 \%(P<0.05)$ a las $72 \mathrm{~h}$. En general, se presentó disminución progresiva de las emisiones de $\mathrm{CH}_{4}$ a medida que aumentó la inclusión de Clitoria ternatea en los ensilados.

\section{DISCUSIÓN}

\section{Análisis químico de los ensilados}

Los valores de MS en los ensilados fueron de
28 hasta $33 \%$, consideradas como cantidades adecuadas (Reyes et al. 2018). Estudios realizados por otros autores reportan aumento en el contenido de MS en ensilajes de pastos cuando se agrega melaza como aditivo (Rusdy 2015) o cuando se incluyen leguminosas en ensilajes de pastos tropicales (Ojeda y Díaz 1991). En este estudio, la asociación entre la melaza y el contenido de nitrógeno con 30 y $40 \%$ de Clitoria ternatea, fueron suficientes para que las bacterias lácticas mantuvieran su tasa de proliferación. El contenido de proteína cruda de los ensilados coincidió con un estudio donde se evaluó la inclusión de 30 y $45 \%$ de leguminosas en ensilados de pastos tropicales (Cárdenas et al. 2003); aunque también se reporta porcentajes de proteína cruda mayores a $12 \%$ en ensilados mixtos de pastos con $30 \%$ de leguminosas (Blanco et al. 2005). Como se mencionó, el ensilado con $20 \%$ de Clitoria ternatea y ácido fosfórico (C20f) mejoró el contenido de proteína, aunque este mismo efecto no sucedió en los ensilados con $40 \%$ de Clitoria ternatea (40 y C40f) posiblemente hay una tasa máxima de degradación donde el fósforo activa las bacterias ácido lácticas y mejoran la disponibilidad del nitrógeno (MetzlerZebeli et al. 2018).

La inclusión de $40 \%$ de Clitoria ternatea en los ensilados disminuyeron los porcentajes de FDN y FDA, investigaciones similares también reportan porcentajes menores de FDN y FDA (Blanco et al. 2005, Nunes et al. 2007). Así, se deduce que la disminución de las proporciones de FDN y FDA en los ensilados con $40 \%$ de Clitoria ternatea, es por las menores cantidades de celulosa y hemicelulosa que contienen 
Tabla 2. Características de la fermentación de los ensilados mixtos de King grass CT115 con Clitoria ternatea.

\begin{tabular}{|c|c|c|c|c|c|c|c|}
\hline Componentes & C20f & $\mathrm{C} 20$ & C30f & C30 & C40f & $\mathrm{C} 40$ & EEM $^{1}$ \\
\hline $\mathrm{pH}$ & $3.80^{a}$ & $4.16^{b}$ & $4.17^{b}$ & $4.39^{b}$ & $4.10^{a b}$ & $4.40^{b}$ & 0.06 \\
\hline \multicolumn{8}{|l|}{$A G V^{2}$} \\
\hline Acético & $0.92^{b}$ & $1.16^{a b}$ & $1.38^{a}$ & $1.22^{a b}$ & $1.19^{a b}$ & $1.04^{b}$ & 0.03 \\
\hline Propiónico & $0.51^{c}$ & $0.73^{b c}$ & $1.06^{a}$ & $0.97^{a b}$ & $0.78^{a b c}$ & $0.60^{c}$ & 0.05 \\
\hline Butírico & $0.23^{b}$ & $0.36^{a b}$ & $0.57^{a}$ & $0.46^{a b}$ & $0.38^{a b}$ & $0.22^{b}$ & 0.02 \\
\hline $\mathrm{NA}^{3}, \% \mathrm{~N}$-Total & $1.61^{e}$ & $2.00^{d}$ & $2.46^{c}$ & $3.16^{b}$ & $2.71^{c}$ & $3.91^{a}$ & 0.18 \\
\hline \multicolumn{8}{|c|}{ abcde Medias con literales diferentes en la misma hilera indican diferencia $(P<0.05) .1$} \\
\hline \multicolumn{8}{|c|}{$\begin{array}{l}\text { Nitrógeno Amoniacal. C20f: } 75 \% \text { de King Grass }+20 \% \text { de Clitoria ternatae }+4.5 \% \text { de } \\
\text { melaza }+0.5 \% \text { de ácido fosfórico. C20: } 75 \% \text { de King Grass }+20 \% \text { de Clitoria ternatae } \\
+5.0 \% \text { de melaza. C30f: } 65 \% \text { de King Grass }+30 \% \text { de Clitoria ternatae }+4.5 \% \text { de } \\
\text { melaza }+0.5 \% \text { de ácido fosfórico. C30: } 65 \% \text { de King Grass }+30 \% \text { de Clitoria ternatae } \\
+5.0 \% \text { de melaza. C40f: } 55 \% \text { de King Grass }+40 \% \text { de Clitoria ternatae }+4.95 \% \text { de } \\
\text { melaza }+0.05 \% \text { de ácido fosfórico. C40: } 55 \% \text { de King Grass }+40 \% \text { de Clitoria ternatae } \\
+5.0 \% \text { de melaza. }\end{array}$} \\
\hline
\end{tabular}

Tabla 3. Degradabilidad de la materia seca, producción de metano y dióxido de carbono durante la fermentación ruminal in vitro de ensilados mixtos de King grass CT-115 y Clitoria ternatea durante diferentes horas de incubación.

\begin{tabular}{crrrrrrr}
\hline Componentes & C20f & C20 & C30f & C30 & C40f & C40 & EEM $^{1}$ \\
\hline $\begin{array}{c}\text { DIVMS }^{\dagger}, \% \\
\mathrm{CH}_{4}, \mathrm{~mL} \mathrm{~g} \mathrm{MS}^{-1}\end{array}$ & $51.28^{a}$ & $53.13^{a b}$ & $54.79^{b}$ & $51.93^{a b}$ & $53.23^{a b}$ & $53.60^{a b}$ & 0.36 \\
24 h & & & & & & & \\
$48 \mathrm{~h}$ & $53.19^{a}$ & $44.49^{a}$ & $43.29^{a}$ & $38.59^{b}$ & $36.99^{b}$ & $31.66^{c}$ & 0.41 \\
$72 \mathrm{~h}$ & $58.60^{a}$ & $50.05^{b}$ & $48.59^{b}$ & $43.89^{c}$ & $41.35^{d}$ & $35.89^{e}$ & 0.43 \\
$\mathrm{CO}_{2}, \mathrm{~mL} \mathrm{~g} \mathrm{MS}^{-1}$ & & $50.03^{b}$ & $45.20^{c}$ & $45.42^{c}$ & $37.36^{d}$ & 0.64 \\
$24 \mathrm{~h}$ & $206.10^{a}$ & $202.87^{a}$ & $197.40^{a}$ & $173.97^{b}$ & $168.67^{b}$ & $144.23^{c}$ & 2.00 \\
$48 \mathrm{~h}$ & $243.77^{a}$ & $223.67^{b}$ & $221.57^{b}$ & $200.14^{c}$ & $188.55^{d}$ & $163.66^{e}$ & 1.96 \\
$72 \mathrm{~h}$ & $267.22^{a}$ & $232.24^{b}$ & $228.14^{b}$ & $206.11^{c}$ & $191.80^{d}$ & $170.36^{e}$ & 2.95 \\
\hline
\end{tabular}

abcde Medias con literales diferentes en la misma hilera indican diferencia $(P<0.05)$. ${ }^{1}$ EEM: Error estándar de la media. ${ }^{\dagger}$ DIVMS: Degradabilidad in vitro de la materia seca. C20f: $75 \%$ de King Grass $+20 \%$ de Clitoria ternatae $+4.5 \%$ de melaza $+0.5 \%$ de ácido fosfórico. C20: $75 \%$ de King Grass + $20 \%$ de Clitoria ternatae $+5.0 \%$ de melaza. C30f: $65 \%$ de King Grass $+30 \%$ de Clitoria ternatae + $4.5 \%$ de melaza $+0.5 \%$ de ácido fosfórico. C30: $65 \%$ de King Grass $+30 \%$ de Clitoria ternatae + $5.0 \%$ de melaza. C40f: $55 \%$ de King Grass $+40 \%$ de Clitoria ternatae $+4.95 \%$ de melaza $+0.05 \%$ de ácido fosfórico. C40: $55 \%$ de King Grass $+40 \%$ de Clitoria ternatae $+5.0 \%$ de melaza.

las leguminosas a diferencia de las gramíneas (Calsamiglia 1997, López et al. 2001). La adición de melaza a los ensilados mixtos con leguminosas es una fuente importante de energía y actúa como estimulante de la fermentación. En este estudio se deduce que la melaza activó la proliferación de las bacterias acidolácticas, incrementándose la concentración de ácidos orgánicos y bajando el pH del ensilado a menos de 4.5 (Heinritz et al. 2012, Hafner et al. 2013). En general, el contenido de ácido acético de este estudio fue inferior a $1.5 \%$ de MS, característica deseable en un ensilaje de buena calidad (McDonald et al. 2011). Resultados similares se reportaron en ensilados mixtos de Ryegrass y trébol (De- whurst et al. 2003). En contraste, también hay un estudio indicando el nivel máximo de $2.9 \%$ de ácido acético en ensilajes mixtos de gramíneas y leguminosas (Cárdenas et al. 2003). La cantidad de ácido acético en los ensilados de este estudio indican la actividad de una fermentación láctica, debido a que los contenidos de ácido acético fue menor a 2.0\% (McDonald et al. 2011), ácido propiónico inferior a 1.0\% (Cárdenas et al. 2003) y ácido butírico menor al $0.6 \%$ de la MS. Heinritz et al. (2012) reportaron cantidades menores a $4.0 \%$ de AGV y nivel máximo de $0.6 \%$ en ácido butírico, cuando se adicionó $5.0 \%$ de melaza a ensilados de leguminosas; datos coincidentes con el presente estudio realizado. 
La concentración de NA como porcentaje de nitrógeno total, fue menor a $4.0 \%$ en todos los ensilados. A medida que aumentó la inclusión de Clitoria ternatea se incrementó la concentración de NA. En contraste, otros estudios reportan variaciones en el NA, por ejemplo, Suárez et al. (2011) hallaron un contenido de NA mayor a $18 \%$ en ensilados mixtos de gramíneas y leguminosas. Clavero y Razz (2011) reportaron la cantidad de NA menor a $1.0 \%$ en ensilados mixtos de King grass y Leucaena leucocephala. Comúnmente, los ensilados con fermentación láctica tienen un contenido de NA inferior a 8\% (Cárdenas et al. 2003, Blanco et al. 2005). En el estudio realizado, la menor producción de NA en C20f, C20 y C30f posiblemente fue debido a la actividad del ácido fosfórico, ocasionando proteólisis y la rápida disminución del $\mathrm{pH}$ en los ensilados (Chaverra y Bernal 2001, Ellis et al. 2016).

En el caso de la DIVMS, los tratamientos no sobrepasaron el valor de 55\%. Otros estudios reportan datos similares (Cárdenas et al. 2003) en ensilados mixtos de gramíneas y leguminosas, cuando se comparan con ensilados de forrajes únicos (Cárdenas et al. 2003). La DIVMS en ensilados de leguminosas o gramíneas depende de las especies y proporciones usadas (Yahaya et al. 2002).

\section{Fermentación in vitro de los ensilados}

En este estudio la DIVMS de los ensilados no presentó cambios a medida que aumentó la inclusión de Clitoria ternatea, esta respuesta posiblemente se debió a que cantidades de FDA y FDN no fueron suficientes para modificar las poblaciones microbianas en el rumen (Betancourt et al. 2002). Sin embargo, la inclusión de Clitoria ternatea hasta $40 \%$ en los ensilados, tuvo efecto para reducir las emisiones de $\mathrm{CH}_{4}$ y $\mathrm{CO}_{2}$ en $27 \%$; resultados similares se han observado con fermentaciones in vitro a $72 \mathrm{~h}$ en ensilados mixtos de Ray grass y trébol (Blanco et al. 2005), lo cual indica que las leguminosas como la Clitoria ter- natea, alfalfa y el trébol durante las primeras $24 \mathrm{~h}$ de fermentación ruminal, producen mayor volumen de $\mathrm{CH}_{4}$ (Muck et al. 2007). Los ensilados de gramíneas tropicales tienen mayor contenido de paredes celulares y al fermentarse contribuyen al aumento de las emisiones de $\mathrm{CH}_{4}$ (Ley et al. 2018). Los resultados del estudio indican que la producción de gas $\left(\mathrm{CH}_{4} \mathrm{y}\right.$ $\mathrm{CO}_{2}$ ) aumentó con el tiempo de fermentación in vitro de los ensilados, pero disminuyó cuando se incrementó el nivel de Clitoria ternatea. Archiméde et al. (2011) señalan que el uso de leguminosas tropicales en la dieta de los rumiantes reduce las emisiones de $\mathrm{CH}_{4}$ debido a que poseen mayor contenido de nitrógeno. Por su parte, Shibata y Terada (2010), indican que es posible reducir la producción de $\mathrm{CH}_{4}$ cuando se aumenta el nivel de proteína en la dieta de los rumiantes. Aunque la producción de $\mathrm{CH}_{4}$ está estrechamente relacionada con la composición química de la dieta y la interacción entre los ingredientes durante la fermentación ruminal (Cobos et al. 2018).

\section{CONCLUSIONES}

La inclusión de 30 y $40 \%$ de Clitoria ternatae en ensilados mixtos de King grass-CT-115 incrementaron la cantidad de materia seca y proteína cruda, disminuyendo el contenido de FDN y FDA. La fermentación del ensilaje, no afectó la producción de NA (menor a $4.0 \%$ ). La cantidad de $40 \%$ de Clitoria ternatea en el ensilado disminuyó en $27 \%$ las emisiones de $\mathrm{CH}_{4}$ y $\mathrm{CO}_{2}$ durante la fermentación ruminal in vitro. La adición de ácido fosfórico a los ensilados produjo disminución de la degradación de proteína y del NA. En esta investigación se comprobó que la Clitoria ternatae es una opción para mejorar la calidad nutricional del ensilaje de King grass y reducir las emisiones de $\mathrm{CH}_{4}$ y $\mathrm{CO}_{2}$ durante la fermentación ruminal in vitro.

\section{LITERATURA CITADA}

AOAC (1995) Official Methods of Analysis. 17th ed. Association of Official Analytical Chemists. Arlington, VA. $1298 p$. 
Archiméde $H$, Eugène $M$, Marie Magdeleine $C$, Boval $M$, Martin C, Morgavi DP, Lecomte P, Doreau M (2011) Comparison of methane production between $\mathrm{C} 3$ and $\mathrm{C} 4$ grasses and legumes. Animal Feed Science and Technology 167: 59- 64.

Barros RMA, Solorio SFJ, Sandoval CCA, Ahmed AMM, Rojas HR, Briceño PEG, Ku VJC (2014) Effect of intake of diets containing tannins and saponins on in vitro gas production and sheep performance. Animal Production Science 54: 1486-1489.

Betancourt de FM, Clavero T, Razz R (2002) Características nutritivas del ensilaje de Leucaena leucocephala con diferentes aditivos. Revista Científica 12: 502-504.

Blanco GM, Chamorro DR, Arreaza L (2005) Evaluación nutricional del ensilaje de Sambucusperuviana, Acacia decurrens y Avena sativa. Revista Corpoica 6: 82-85.

Bugarín J, Lemus C, Sangines L, Aguirre J, Ramos A, Soca M, Arece J (2009) Evaluación de dos especies de Leucaena, asociadas a Brachiaria brizantha y Clitoria ternatea en un sistema silvopastoril de Nayarit, México. II Producción y composición. Pastos y Forrajes 32: 1-7.

Bustamante GJ (2004) Utilización de heno de Clitoria en la alimentación de becerras lactantes de propósito lechero. INIFAP. México. 30p.

Calsamiglia S (1997) Nuevas bases para la utilización de la fibra en dietas para rumiantes. XV curso de Especialización Avances en Nutrición y Alimentación Animal. Fundación Española para el Desarrollo de la Nutrición Animal. Madrid, España. $1^{\text {a }}$ Edición. 16p.

Cárdenas MJV, Castro CAS, Sandoval CCA, Solorio SFJ (2003) Composición química de ensilajes mixtos de gramíneas y especies arbóreas de Yucatán, México. Técnica Pecuaria México 41: 283-294.

Carmona JC, Bolivar DM, Giraldo LA (2005) El gas metano en la producción ganadera y alternativas para medir sus emisiones y aminorar su impacto a nivel ambiental y productivo. Revista Colombiana de Ciencias Pecuarias 18: 49-63.

Carulla JE, Kreuzer M, Machmüuller A, Hess HD (2005) Supplementation of Acacia mearnsii tatannin decreases methanogenesis and urinary nitrogen in forage-fed sheep. Australian Journal Agriculture Research 56: 961-970.

Chaverra G, Bernal JE (2001) Ensilaje en la alimentación de ganado vacuno. IICA. Tercer Mundo Editores. Bogotá, Colombia 123p.

Clavero T, Razz R (2011) Compuestos nitrogenados y características fermentativas de ensilajes de mezclas de King Grass-Leucaena leucocephala. Revista de la Facultad de Agronomía LUZ 28: 83-88.

Cobos MA, Curzayns KR, Rivas MI, Santillan EA, Barcena JR (2018) Efecto in vitro de dietas para corderos más un suplemento de granos secos de destilería en la fermentación ruminal y emisión de gases. Agrociencia 52: 203-215.

Dewhurst RJ, Fisher WJ, Tweed JKS, Wilkins RJ (2003) Comparison of grass and legume silages for milk production. 1 Production responses with different levels of concentrates. Journal Dairy Science 86: 2612-2621.

Dunière L, Sindou J, Chaucheyras DF, Chevallier I, Thévenot SD (2013) Silage processing and strategies to prevent persistence of undesirable microorganisms. Animal Feed Science and Technology 182: 1-15.

Ellis JL, Bannink A, Hindrichsen IK, Kinley RD, Pellikaan WF, Milora N, Dijkstra J (2016) The effect of acid bacteria included as a probiotic or silage inoculants on in vitro rumen digestibility, total gas and methane production. Animal Feed Science and Technology 211: 61-74. 
Goering HK, Van-Soest FJ (1970) Forage fiber analysis (apparatus, reagents, procedures and some aplications). USDA. Agricultural Handbook Vol. 379, Whashinton D.C. USA. 20p.

Hafner SD, Howard C, Muck RE, Franco RB, Montes F, Green PG, Mitloehnerd F, Trabuef SL, Rotza CA (2013) Emission of volatile organic compounds from silage: Compounds, sources, and implications. Atmospheric Environment 77: 827-839.

Heinritz SN, Martens SD, Avila P, Hoedtke S (2012) The effect of inoculant and sucrose addition on the silage quality of tropical forage legumes with varying ensilability. Animal Feed Science and Technology 174: 201210.

Hill J, McSweeney C, Wright ADG, Bishop HG, Kalantar ZK (2016) Measuring methane production from ruminants. Trends Biotechnology 34: 26-35.

Juárez RA, Cerrillo SM, Gutiérrez OE, Romero TE, Negrete CJ, Bernal BH (2009) Estimación del valor nutricional de pastos tropicales a partir de análisis convencionales y de la producción de gas in vitro. Técnica Pecuaria México 47: 55 - 67.

Krabill LF, Alhassan WS, Satter LD (1969) Manipulation of the ruminal fermentation. 2. Effect of sodium sulfite on bovine digestion and ruminal fermentation. Journal of Dairy Science 52: 1812-1816.

Ley de Coss A, Guerra MC, Montañez VO, Guevara HF, Pinto RR, Reyes GJ (2018) Producción in vitro de gas metano por gramíneas forrajeras tropicales. Revista MVZ Córdoba 23: 6788-6798.

López JL, Mederos CM, Pérez CR (2001) Nota sobre la composición química del follaje de dos variedades de conchita azul (Clitoria ternatea L.) Revista Computadorizada de Producción Porcina 8: 28-35.

McCaughey WP, Wittenberg M, Corrigan D (1997) Methane production by steers on pasture. Canadian Journal of Animal Science 77: 519-524.

McCullough $H$ (1967) The determination of ammonia in whole blood by direct calorimetric method. Clinical Chemical Acta 17: 297-304.

McDonald P, Edwuards RA, Greenhalgh JFD, Morgan CA, Sinclair LA, Wilkinson RG (2011) Ensilado. En: McDonald P (ed.) Nutrición animal. 7a edición. Editorial Acribia. Zaragoza, España. pp: 473-494.

Metzler-Zebeli BU, Haselmann A, Klevenhusen F, Knaus W, Zebeli Q (2018) Lactic acid treatment of by-products and phosphorus level in the diet modulate bacterial microbiome and the predicted metagenome functions using the rumen simulation technique. Journal of Dairy Science 101: 9800-9814.

Muck RE, Filia I, Contreras GFE (2007) Inoculants effects on alfalfa silage: In vitro gas and volatile fatty acid production. Journal of Dairy Science 90: 5115-5125.

Nunes H, Zanine A de M, Machado TMM, de Carvalho FC (2007) Alimentos alternativos na dieta dos ovinos: Uma revisao. Archivos Latinoamericanos de Producción Animal 4: 147-158.

Ojeda GF, Díaz D (1991) Ensilajes de gramíneas y leguminosas para la producción de leche. I. Pannicum máximum cv, Likoni y Lablab purpureus cv. Rongai. Pastos y Forrajes 14: 175-184.

Posada SL, Noguera RR (2018) Técnica in vitro de producción de gases: Una herramienta para la evaluación de alimentos para rumiantes. Livestock Research for Rural Development 17:1-18.

Reyes GJ, Montañez VO, Guerra MC, Ley-De-Coss A (2018) Efecto de la inclusión de aditivos sobre la calidad del ensilado de caña de azúcar. Revista MVZ Córdoba 23: 6710-6717. 
Rusdy M (2015) Effects of additives on fermentation characteristics and chemical composition of ensiled Chromolaena odorata leaves. Livestock Research of Rural Development. 27: 60. http://www.Irrd.org//rrd27/4/rusd 27060.html. Fecha de consulta: 23 de agosto de 2020.

Sánchez ML (2005) Estrategias modernas para la conservación de forrajes en sistemas de producción bovina tropical. Revista Corpoica 6: 69-81.

Santos da Siva W, Carvalho dos Santos TM, Cavalcanti NCC, Espíndola FAM, Mesquita da Silva SG, Figueiredo AN, Araujo de Melo B (2014) Características y estabilidad aeróbica de ensilajes de caña de azúcar, tratada con urea, $\mathrm{NaOH}$ y maíz. Pastos y Forrajes 37: 182-190.

Shibata M, Terada F (2010) Factors affecting methane production and mitigation in ruminants. Animal Science Journal 81: 2-10.

SAS (2010) Statistical Analysis System, User's guide. Version 9.2: SAS Institute. User's Guide: Statistics, Cary, NC, USA Inst. Inc. 60p.

Steel RGD, Torrie JH (1988) Bioestadística: Principios. McGraw Hill, México. 622p.

Suárez R, Mejía J, González M, García DE, Perdomo DE (2011) Evaluación de ensilajes mixtos de Saccharum officinarum y Gliricidia sepium con la utilización de aditivos. Pastos y Forrajes 34: 69-86.

Vargas J, Cárdenas E, Pabón M, Carulla J (2012) Emisión de metano entérico en rumiantes en pastoreo. Archivos de Zootecnia 61: 51-66.

Villanueva AJF, Bonilla CJA, Rubio CJV, Bustamante GJ (2004) Agrotecnia y utilización de la Clitoria ternatea en sistemas de producción de carne y leche. Técnica Pecuaria México 42: 79-96.

Yahaya MS, Kawai M, Takahashi J, Matsuoka S (2002) The effects of different moisture content and ensiling time on silo degradation of structural carbohydrate of Orchardgrass. Journal of Animal Science 15: 213-217. 